\title{
Challenges of Digital Transformation in SMEs: Exploration of IT-Related Perceptions in a Service Ecosystem
}

\author{
Claudia Pelletier, DBA \\ Université du Québec à Trois-Rivières \\ Claudia.Pelletier@uqtr.ca
}

\author{
L. Martin Cloutier, Ph. D. \\ Université du Québec à Montréal \\ cloutier.martin@uqam.ca
}

\begin{abstract}
Supported by a service ecosystem that is increasingly immersed into the digital transformation, SMEs have access to turnkey IT applications, which may come free of charge but not free of concerns. Using the group concept mapping (GCM) as the methodological framework, a concept map was estimated for a group of entrepreneurs in SMEs. Six main themes were identified as conceptual representations. The perceptions of the three main actor groups which interact in the ecosystem (i.e. entrepreneurs, IT specialists, socioeconomic support professionals) were estimated and compared. The analysis of IT-related perceptions shows entrepreneurs tend to rank as relatively more important the IT evaluation support identified on the concept map rather than the nature of the digital strategy to be implemented when compared with IT specialists and socioeconomic professionals. The discussion highlights issues of perceptions which vary among these interacting actors, and stresses the need to develop a shared understanding of IT challenges in a service ecosystem.
\end{abstract}

\section{Introduction}

To better support operations and management activities, and to access resources and skills they do not possess internally, small and medium-sized enterprises (SMEs), with fewer than 20 employees who represent $70 \%$ of all businesses in Canada [1], are under pressure to adopt and use information technology (IT) more intensively. This paper examines issues and challenges in the adoption and use of turnkey IT applications by SMEs from an ecosystem perspective [2].

Based on the need to take the digital shift and improve business competitiveness on the world stage [3], the prevailing discourse carries with it the notion that IT has become more accessible, user-friendly and inexpensive. Indeed, SMEs have access to technology applications in support of business functions, such as marketing (e.g., platforms for e-commerce, including social media applications); finance and accounting (e.g. open source software or mobile secure payment solutions) or human resources (e.g., collaborative tools, such as videoconferencing, shared calendars and instant messaging). These IT can either be completely free or pay per use as they are based on a serviceoriented architecture (SOA) accessible over the Internet [4].

In addition, designed and developed by IT specialists, turnkey IT applications, and their infrastructure, are presented in a way that suggests a reduction in the complexity of management processes, as well as more fruitful customer, supplier and business relationships. As useful and necessary as they may appear to be a priori, the use of this type of IT may pose several important challenges for SMEs: (1) the fair and realistic IT needs assessment [5] and, as a result the coherence of IT choices with respect to business objectives (e.g. IT strategic alignment) [6]; (2) the need for skills required to ensure the management of newly implemented IT [7]; (3) the consideration of a growing complexity in the ecosystem [8], including the establishment and management of relationships with IT specialists and service providers such as socioeconomic support professionals (e.g. management specialists in public organizations).

In parallel with needs of entrepreneurs and the growing IT offer for SMEs and their users, the use of expressions such as "digital transformation" and "digital strategy" is increasing in socioeconomic and political arenas [3]. These new expressions, which definition remain unclear, lead to highly uneven perceptions of issues experienced among actors in ecosystems [5]. Adding to challenges of divergent representations of this phenomenon, the imperative to engage into the digital transformation is presented to SMEs in ways which emphasizes the urgency of largescale and quick actions. To do so, the socioeconomic support professionals are called upon and mobilized to 
offer support, training, and expand the service range [9], especially in the area of digital and innovation support for SMEs across all industrial sectors [1, 3]. Hence, several socioeconomic support organizations are currently expressing the need for clearer definitions and guidelines from all levels of government.

Nevertheless, even with the complementarity of specialized IT products and services offered [10], all actors involved might not hold a common or shared perception regarding issues of IT adoption and use in a business context $[11,12]$, and this problem ought to be investigated to help develop effective digital transformation interventions [5, 13]. The notion of representation based on the concept of sensemaking seems promising to tackle this issue [14]. Specifically, the group concept mapping (GCM) as a methodological framework is employed $[15,16]$. The objective of the study is to explore the different perceptions pertaining to IT and digital transformation issues within an ecosystem that includes entrepreneurs, IT specialists and socioeconomic support professionals. Hence, the research question is: How do three groups of actors interacting in a service ecosystem primarily dedicated to SMEs collectively perceive and assess challenges of digital transformation when adopting and using turnkey IT applications?

Given the growing interdependence and redefinition of relational and communication boundaries in the digital era [17], the research contributions are threefold: (1) identify needs in terms of human, financial and time resources that must be allocated by SMEs; (2) define specific technical skills desirable in this context [9], and (3) focus on the organizational and strategic capabilities that can be supported through better targeted decision-making in IT-oriented socioeconomic interventions [2].

\section{Background}

Several IT-related topics have been studied with two main approaches [11]. One approach focuses on the "what", that is, the "content" related to IT, strategies, structures, and plans that support them. This approach dominates the information system (IS) field [18]. The other approach focuses on the "who", i.e. actors within the organization, their values, beliefs, attitudes, communications, as well as their understanding of issues experienced. Hence, the reasons for the greater relevance of the latter approach to answer the research question are: (1) its coherence with the definition of IS/IT-enabled organizational transformation, which is "a global phenomenon in which psychological, socio-cognitive, sociotechnical, economic and political considerations intertwine" [13] (p. 105); (2) the attention given to actors' cognition which is also relevant to a service-dominant logic (S-D) approach in an ecosystem that relies on actor-toactor (A2A) orientation for value creation [19]; (3) its focus on actors, and their conceptualizations, behaviors and relationships. All of the above is consistent with specificities of the entrepreneurial context, SMEs and their business environments [20, 21].

\subsection{Social and relational dimensions of digital transformation in SMEs}

Digital transformation in SMEs addresses psychological inertia at the individual level (e.g. entrepreneurs), socio-technical inertia at the group level (e.g. IT specialists), and economic and political inertia at the systemic level (e.g. socioeconomic support professionals) [13]. The reasons are threefold. First, the specific and emerging IT needs that result in the increased interdependence of varied and more frequent new relationships among actors working together [22]. Second, the possibility that critical resources or key technological activities for the enterprise and its operations stand outside organizational boundaries [10], especially regarding resources required as input into innovation and services offered [17]. Third, the need to better defined among actor boundaries and conditions which impact activities and exchanges [9]. In other words, given all challenges of digital transformation, SMEs are increasingly in need of specialized IT resources. These resources are accessible in the business environment and on the Internet [4]. Their effective management, however, requires some attention be given to relational [10], social [11], and cognitive dimensions [18]. This is mainly because these resources support the development of new behaviors [23], as much as key IT competences in SMEs [8], jointly with IT specialists and other socioeconomic actors in the ecosystem.

Hence, for SMEs facing digital transformation, the ecosystem is of paramount importance for two main reasons. First, the added value for the enterprise is created mainly by relationships established on a freeform basis rather than based on a vertical chain of command [19, 24]. Second, an emphasis on the relational aspect of IT raises questions on the part of entrepreneurs on elements, both personally and socially important to the enterprise [23]. Indeed, actors are faced with the need to divert their attention away from a product or service process that occupies a significant part of their time, to set up and manage new ones, such as non-existent structures or new relationships induced by turnkey IT applications [17].

The accelerating digital shift places IT specialists in front of two challenging situations regarding social 
interactions among each other or with other actors. First, the need to develop managerial and business competences that may not be aligned with personal and social skills which are inherently more technical in nature [25]. Second, the questioning of certain collective interests, so as to favor a homogenous grouping of specialized professionals [18, 26], a situation that is relatively common in the field of IT and technological ecosystems. Moreover, given an increasingly actor-to-actor and service-oriented perspective where "it's all B2B" [19], IT specialists are called in to design and develop IT applications of commercial value as much for them, as for their customers. From a learning perspective, this situation refers to the development of a type of co-specialization concerning information and know-how between IT specialists and users with the underlying idea of enhancing the lived common experience [10,27]. This corresponds to the "value cocreation framework" where service is defined as a "process of using one's resources for the benefit of another, rather than an output (i.e. an intangible product)" [28] (p. 518). The social aspects surrounding the work of IT specialists interacting with other actors are crucial. Indeed, as documented, it is through shared understanding among actors the 'positive' break-up of functional boundaries regarding learning and IT in the SME context can occur [4, 29].

Finally, with respect to socioeconomic support professionals, particularly the ones focused on financial services, their client needs change and evolve rapidly in response to digital transformation pressures. In other words, they may not feel prepared enough to offer this emerging or higher knowledge-based intervention [3, 9], given the rising strategic importance of IT for SMEs [30]. This includes the clarification of existing guidelines to better adapt existing programs and socioeconomic support interventions to the emerging digital business context and its ecosystem [5].

\subsection{Business ecosystem or service ecosystem?}

Tsujimoto et al. have identified five types of business ecosystems: a) digital; b) complementary (sub-industry); c) supplier; d) business group (M\&A); and e) global professional human networks. Although their definitions may vary, researchers focus on two main elements, namely actors/players concerned (business player networks), their behaviors and the mechanisms acting in the background (network dynamics and patterns) [2] (p. 4). They also distinguish these networks from another type of ecosystem called "multi-actor network" that includes "entrepreneurs and private investors, innovators who are outside of company pipelines, users/user communities, governmental bureaucrats/policy makers, and consortiums" (p. 6). Based on their categorization, the five business ecosystems are actually components of the second type of ecosystem introduced. Thus, they broaden the composition of the group/network formed as well as they distinguish different types of relationships their members hold among them.

A focus on organizational actors makes possible the examination of longer-term IT-related issues [11]. To do this, actors can rely on an increased role for IS/IT [13], or new behaviors and service innovations by actors involved, either at the development or at the deployment phases [17]. Hence, the digital transformation implies a service-dominant (S-D) logic [28]. In short, this orientation is specifically based on networks of actors involved in a given system. Their behaviors and relationships they establish make possible the joint resource integration rather than the maintenance of a more limited producer/consumer relationship. Thus, it is through the exchange of IT resources and specific skills and knowledge which come along with them, that various actors (entrepreneurs, managers, IT specialists, specialized stakeholders, consultants, etc.) build value as part of a cocreation process. In other words, the S-D logic of digital transformation goes beyond the microeconomic perspective of the traditional business ecosystem of customers, suppliers and other stakeholders with hierarchical or strictly complementary relationships $[19,28,31]$.

To summarize, the digital transformation from a service ecosystem perspective is based on actors not fundamentally different, but who exchange skill and knowledge resources of various kinds to meet specific needs [32]. We no longer refer to resource production/consumption, but to the resource integration between organizations during exchanges whose coordination is based on "rules of the game" shared by the actors. [19, 31]. This supports a complex vision of the digital transformation process that begins with humans in relation to each other and not exclusively on technological artifacts $[10,13]$. Given this, the ecosystem of interest is based on the S-D logic of a service/multi-actor ecosystem [2, 19].

\subsection{Challenges of digital transformation in SMEs}

One of the challenges of adopting, using and managing turnkey IT applications in SMEs, is the struggle to assess IT needs, as much as the contingencies to which they are exposed $[8,21]$. SMEs often achieve mixed results because IT value creation 
is way more difficult than anticipated at the onset by entrepreneurs and managers. This situation may seem paradoxical given IT is unavoidable [7], and is sometimes directly imbedded in the business model of firms [33]. In addition, turnkey IT applications are usually offered through a service-oriented architecture (SOA) [34], so companies can access different features and set options at various costs. There is a number of explanations for this. First, the difficulty for SMEs to achieve a strategic alignment of IT through technology choices consistent with business objectives [29]. Second, a one-size-fits-all approach to the adoption and use of IT that does not take into account specific needs and expectations of entrepreneurs and SMEs, as well as their specific characteristics and contingencies from the environment [21]. Third, a focus that remains on operations within a short time horizon [20]. Fourth, a perception limited to IT as a "commodity" [30]. Fifth, informal management practices that restrict the use of IT for greater strategic purpose [8]. Finally, a business context within which it is not uncommon that IT resources and technological competences are underestimated, poorly perceived and presented, idealized, fragmented or simply misunderstood by entrepreneurs and managers as well as by internal and external actors $[11,25]$.

In other words, SMEs have access to turnkey IT applications that support a number of business functions (e.g. Google Analytics for marketing; Amazon, PayPal for e-commerce or other social media solutions, including Facebook which offers a range of features for SMEs; Skype, Teamviewer and Messenger for collaboration, etc.). Nevertheless, as useful and necessary as they appear at first glance, the adoption and use of these IT by SMEs pose significant challenges to strategies and processes they require upfront [7, 20]. Emerging needs include indispensable relationships with IT specialists and different service providers, such as socioeconomic support professionals. Hence, exchanges between all these actors could at times be difficult, given the lack of shared terminology and language [25], or even a common understanding of business issues and needs $[11,12]$.

\subsection{Making sense of digital transformation}

On the one hand, the emergence and intensification of the use of IT for digital transformation, and the shift from a traditional "producer/consumer" ecosystem (e.g. business ecosystem) has become more challenging for SMEs [7]. One the other hand, the entrepreneur who wants to ensure business success is also strongly encouraged by public and support organizations to initiate a rapid "digital transformation", as well as to elaborate a deliberate "digital strategy" [3]. Based on an increased use of IS/IT that involves different opportunities for innovation, specifically for service innovation [17], organizational transformation is "understood as a process that engenders a qualitatively different organization" [13] (p. 103). In an actor-to-actor (A2A) orientation for value creation [19], the ecosystem offers a wide range of resources and services through IT specialists and various suppliers and professionals (e.g. service/multi-actor ecosystem). These represent major challenges given the growing strategic role of IT specialists $[2,34]$. The situation has also evolved for socioeconomic support professionals who must reconsider their roles as well as the nature of their interventions [9].

Thus, all actors involved ought to (re)evaluate their exchange modes given resource integration, including the way they manage multiple actors in a "real" service ecosystem [28, 31]. In other words, a context such as a service ecosystem should be based on "relatively self-contained, self-adjusting system of resourceintegrating actors connected by shared institutional arrangements and mutual value creation through service exchange." [28] (p. 518). To do this, the exploration of shared ideas [18], common interests [26], shared languages, including terminology used by various actors [12, 25], symbols, institutions and technology that interface with the actor needs [19] as well as dimensions of IS-enabled organizational transformation which relate to inertia and/or sociotechnical path dependencies is key [13].

Given what precedes, the use of representations based on the notion of sensemaking appears promising [14]. Specifically, because representations are useful to study: (1) cognitive elements, behaviors, and relationships [23, 33]; (2) decision-making in a dynamic environment [26] and, finally (3) similarities and differences displayed by managers in managerial, strategic and technological terms [18].

\section{Methods}

Relevant for examining the collective or group aspects related to IT [18], the present study employs the group concept mapping approach. The GCM is a mixed methods-based approach (qualitative/ quantitative) employed with groups of participants. It is used to highlight deliberate and unintentional learning systems, as well as complex interactions among underlying dimensions of business and service ecosystems, including those of very small enterprises/SMEs [35]. The GCM method appears in the field of program planning and evaluation where it was first introduced [36, 37].

Based on a group construction of the reality experienced by actors in the service ecosystem [11], 
the GCM is used to study the adoption and use of turnkey IT applications. The method consists in estimating the representations, on the one hand, and to evaluate the perception, on the other hand, of the various issues associated with the digital transformation from the perspective of entrepreneurs, IT specialists, and socioeconomic support professionals. There are six methodological steps as part of the methodological framework as conducted in this study.

Step 1 Preparing for GCM was conducted with a steering committee established for the project. It included the research team and socioeconomic actors involved in delivering IT training for entrepreneurs and SMEs. This step is for the purpose of timeline definition and logistical planning, as well as to identify participants. It was decided that three groups of actors would be recruited for the study: entrepreneurs, IT specialists, and socioeconomic support professionals.

For Step 2 Generating the ideas, group discussions (GD), taking the form of brainstorming sessions, were held. A total of six (6) GDs were held with $n=39$ participants in total. During GDs, participants were prompted to share ideas to complete the following sentence: "Regarding the use of turnkey IT applications and electronic platform, a particular issue for my organization would be....". After ideas were collected and synthesized, a total of 90 items were formalized. Examples of statements obtained during GDs are: 'To use IT to develop my enterprise'; 'To measure the impact of IT tools (e.g. ROI, sales, performance)'; 'To link my expectations with the reality of apparent user-friendly IT turnkey platforms'; 'To be better informed about available IT training'; and 'To establish transparent communications between entrepreneurs and IT specialist about expectation and deliverables to avoid a deception'.

The Step 3, Structuring the items, was conducted in person with entrepreneurs as the chosen participants' profile to estimate its conceptual representation. Three tasks were completed by this group of participants. Task 1 included a short contextual survey. For Task 2, participants were asked to sort the 90 -item deck of cards provided into piles to organize them based on the conceptual proximity of contents. The Task 3 included rating items on two 5-point Likert type scales to obtain perception measures of relative importance and relative feasibility ( $1=$ not important/not feasible, and $5=$ extremely important/extremely feasible). For this task, the rating data were also collected from 14 IT specialists, and from 14 socioeconomic support professionals so that perception measures could be estimated for all three groups.

The Step 4 Estimating concept maps includes multivariate statistical estimations using the software
CS Global MAX® (www.conceptsystems.com). First, the data collected during Task 2, Step 3, organized in a total similarity matrix formed with participants' item sorts were analyzed using non-metric multidimensional scaling analysis (MDS) [38], to generate the bidimensional $X, Y$ coordinates of the group's dot map spatial structure. Second, the $X, Y$ coordinates of the dot map are used to conduct hierarchical agglomerative cluster analysis (HCA) [39], so that non-overlapping clusters can be identified on the resulting group concept map for interpretation and use.

Step 5 Interpreting the maps takes the results from the Step 4 back to the steering committee supplemented with additional interested participants to determine and interpret the 'definitive' concept map. There are two reasons for this. First, participants are given the printout from the HCA starting from 12 down to 5 clusters. For example, the printouts include the list of items on a per cluster basis, showing at each iteration the merger between two clusters on the concept map. The role of the HCA is to help determine the spatial conceptual proximity between clusters of items in a strictly statistical sense. Second, participants debrief among them about the conceptual proximity of the proposed cluster merger and decide whether items on these clusters ought to be merged or not. The exercise was conducted with entrepreneurs' HCA outputs of item sorts. During the group debriefing discussion, participants settled on a six cluster representation (a stylized version of the final concept map is in Figure 1, section 4.1). Given clusters are formed of items, and the HCA results reveal where they are located on the concept map, the scale results are averaged out for each item. It becomes possible to determine perceptions the three groups hold about the various themes each cluster represents, and to compare them. Illustrative results comparing the relative importance for each cluster by actor profiles are displayed in Figure 2, section 4.2.

The Step 6 Answering questions uses the estimated group concept map (representation) to analyze associated perceptions, from both a theoretical and a practical managerial perspective for all three groups (entrepreneurs; IT specialists and socioeconomic support professionals).

\section{Results}

This section includes two sets of results. The group concept map conceptual framework for entrepreneurs is described in section 4.1, and the relative importance rating by clusters across actor profiles (entrepreneurs, IT specialists, and socioeconomic support professionals) are presented in section 4.2. 


\subsection{Entrepreneurs' conceptual framework}

The group concept map as determined by entrepreneurs comprises six non-overlapping clusters (see Figure 1), where the number of items in each one is reported in brackets, and these are:

- Digital Strategy (12)

- IT Evaluation and support (13)

- IT Expectations and Deliverables (25)

- IT Competence Development (15)

- IT Use and Understanding (13)

- IT-Related Attitudes and Behavior (12)

Each cluster comprises a number of items that were allocated to them based on the HCA. The GCM results, unlike most alternative concept mapping methods, are bottom-up, participative, rather than top-down. This means they are based on statistical estimation, from participants' content coding, rather than on researchers' content coding. Thus, it is depicting a complex system [40]. The stress value, a measure of internal statistical reliability is 0.29 ; which is considered appropriate within the range expected in GCM pool studies [16].

The map shows that as part of their representation, entrepreneurs have placed the Digital Strategy at the center of their systemic representation and it includes 12 items. Technically, all other concepts emerge from the center of that system and go back to it [40]. On this cluster, the item "Use IT to develop my enterprise" is right at the center of the concept map. Other items relate to setting IT objectives in relation to revising business objectives; invest in IT from a qualitative standpoint (purpose, timing); and taking the required time to determine the various options that meet the business strategic objectives.

A cluster is dedicated to the notion IT Evaluation Support and this one includes 13 items. This cluster addresses all types of "evaluation" support needed, including: determination of the appropriate online marketing performance measures; enterprise brand and image; online contents; information updating; and striking the right balance in between IT usefulness and ROI.

IT Expectations and Deliverables is a 25-item cluster, the most densely constituted. This cluster highlights elements of the relationships between entrepreneurs and IT specialists. Some of these include: the need to establish and maintain transparent discussions between entrepreneurs and IT specialists regarding deliverables; the quality/price ratio for the type of business; simple language communication; optimal service levels.

The IT Competence Development cluster has 15 items to describe the different types of training needed about IT, fulfilling both customized and general IT-related needs. Some of these relate to general knowledge about IT, or more specific technical information, which can be obtained from interactions and communications with socioeconomic support professionals.

The IT Use and Understanding is a cluster of 13 items. Some of them concern the choice of the appropriate IT application and the determination of the use of IT associated to specific business needs, and as well as making sure that legal and technical aspects, and that metadata produced by IT applications are part of what needs to be managed.

Last, but fundamental, the IT-Related Attitudes and Behavior cluster includes dimensions such as the blurring of the frontier between the personal and the professional life and imperatives; the need to dedicate more time to the passion underlying the business than to IT management; social media crisis avoidance; and to set expectations at the appropriate level regarding the adoption and use of turnkey IT applications.

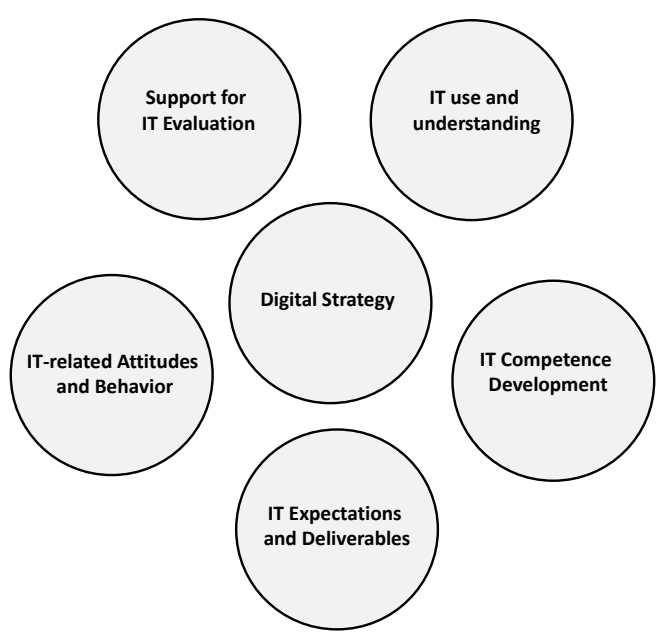

Figure 1. Conceptual representations of entrepreneurs 


\subsection{Pattern matches between actors' perception of relative importance}

The figure 2 presents and compares the pattern matches regarding the relative importance of each cluster of the concept map between the three groups, on the five-point scale.

There are a few distinguishing features in this graph. First, the entrepreneurs rank first the $I T$ Evaluation Support, while IT specialists and socioeconomic support professionals perceived the Digital strategy as relatively more important. Both IT specialists and socioeconomic support professionals considered that the Digital Strategy ought to be the top priority.

Second, the IT Expectations and Deliverables; IT Competence Development; and IT Understanding and Use clusters were considered, in absolute terms relatively less important by entrepreneurs than by the other two profiles. But their relative ratings were similar among them on the scale.

Finally, it would be interesting to further investigate why all three groups have rated, as relatively low IT-related Attitude and Behavior.

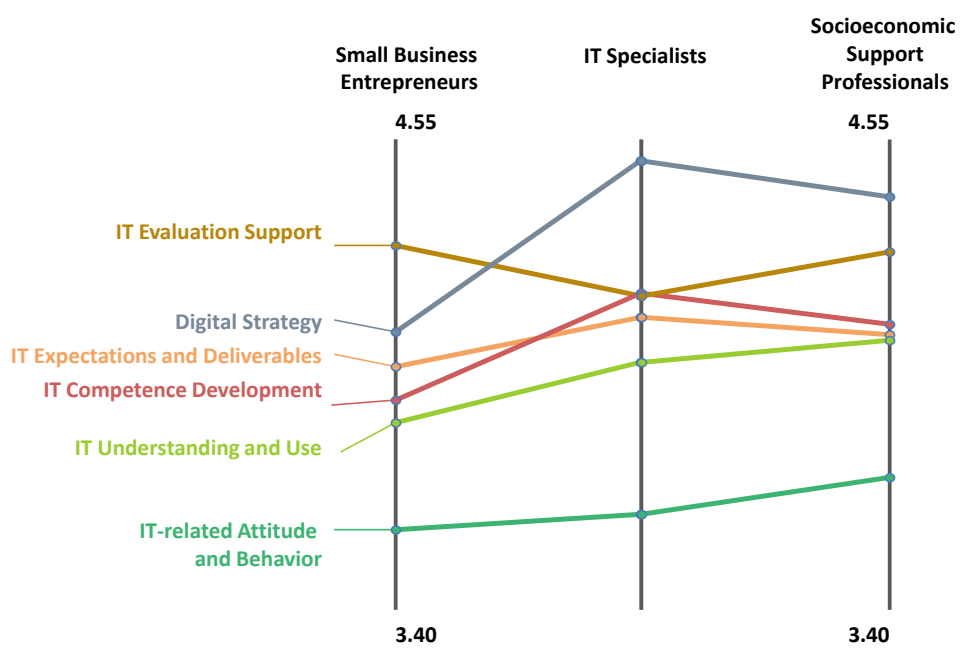

Figure 2. Pattern matches per actor profile of relative importance: Entrepreneurs, IT specialists, Socioeconomic support professionals

\section{Discussion}

The results highlight how IT issues are perceived and evaluated in different ways, depending upon one's position in the ecosystem (i.e., entrepreneurs, IT specialists, socioeconomic support professionals). These types of disparities among all actors are documented in the IS/IT literature [25]. However, they had not been examined on the semantic front where they refer to the common language shared between groups. Following Reich and Benbasat (2000), the terminology used by different groups has an impact on the language shared (or not) between actors [12]. Hence, the results startlingly show there remains work to be done to ensure that digital transformation actors can achieve more effective communication exchanges that will, in turn, support more fruitful relationships to sustain competitiveness [10], including innovation in their respective service offers [17]. In addition, the issues identified by entrepreneurs, IT specialists and socioeconomic support professionals can overlap in a number of ways, yet the assessment of the relative importance of their respective action set reveals an essential linkage regarding actors' success and the one the ecosystem.

From a relational view, to generate a real competitive advantage four conditions must be met by its actors: (1) invest in specific relationship-type assets, hence the use of turnkey IT applications designed and developed outside the enterprise; (2) have an exchange of knowledge through collaborations or services that extend beyond the boundaries of the enterprise; (3) combine resources and capabilities into inimitable assets, which respect the idiosyncrasy of SMEs needs to offer differentiated products/services to various markets based on different strategies; and (4) lower transaction costs through "unified" governance with socioeconomic actors called in to play a new role as digital support professionals [10]. For example, through interventions 
which cover both the explicit (information) and the tacit (know-how) IT components [41]. Given the S-D logic, this situation means the ecosystem is built on: (1) service as a fundamental basis of exchanges; (2) value cocreation by multiple actors; (3) integration of resources by all social and economic actors; (4) value that is determined by the beneficiary, and (5) value cocreation that is coordinated through "shared institutions" (e.g. social norms, rules, symbols and other normative and heuristic guidelines) $[19,28$, $31]$.

At the conceptual level, individual intervention support programs allow to act on the idiosyncratic elements, whereas those made in groups rather aim at elements of similarities [18]. In any case, better targeted interventions, given empirical results, cover the intellectual (knowledge), social (mutual commitment) and relational (transfer) dimensions required to ensure greater long-term technological and strategic coherence $[6,11]$. By doing so, socioeconomic support professionals could act as a catalyst between SMEs and IT specialists when sharing knowledge [10, 27], even if the environment remains dynamic [26].

Finally, there is a common thread to the three groups of actors examined in terms of adoption, use and technological change. More specifically, although interactions are growing between actors, communications, as much as service exchanges are still struggling to be established in ways that are really rooted in the recommended sociotechnical approach to IS/IT [10, 13]. Thus, it is important for IT specialists to be cognizant of two things: (1) the "dependence" of SMEs on their products and services will vary greatly based on their specific needs [21], and (2) the concrete (or not) contribution of IT to the competitive advantage of some SMEs [27]. In other words, are turnkey IT applications adopted and implemented by SMEs complementary resources of a strategic nature for intra or inter-organizational service innovation? [17]; or are they for additional organizational resources? [10]; or are they simple operational commodities? [30]. The anticipated answer to these questions is also central to explaining priority differences highlighted between the relative importance of issues identified by entrepreneurs, IT specialists and socioeconomic support professionals in the study. To summarize, the results precisely target the importance of social interactions and user perceptions for IS development and implementation and/or adoption and use of existing IT [33].

\section{Contributions and future research}

Despite the repeated interest for the "who" approach in IS/IT-related research [11] it remains seldom used to study complex phenomena such as digital transformation [13, 23]. Founded on the perception measures obtained from three groups of actors of a service ecosystem whose main activities are dedicated to SMEs, the theoretical contributions of the research allow for a more precise identification of issues facing SMEs in turnkey IT applications adoption and use. In doing so, the contribution of the GCM framework highlighted the complex interactions found in such a context. Also, the results provide a better understanding of the boundaries and relationships that exist between entrepreneurs, IT specialists, as well as socioeconomic professionals providing support services, a situation more commonly found in SMEs in the digital age.

On the practical front, the research contributes to the awareness, and offers a broader reflection about IT and digital transformation challenges on the part of entrepreneurs. For IT specialists, the sharing and transfer of knowledge among participants to the identified challenges of using turnkey IT applications already suggests the importance of developing and using a more common vocabulary and a language that is closer to the business management going concerns [25]. For socioeconomic support professionals, the aim is to be in a better position to develop programs which support the digital shift with interventions focused on similarities and differences that emerge among SMEs [19], and this, whether they are working in different business sectors, they already use turnkey TI applications or simply anticipate doing so.

Further analysis of issues already identified could focus on understanding established relationships as well as desirable behaviors and decision-making principles for all actors in the ecosystem examined [2, 17, 26]. As seen, this includes an in-depth investigation of some specific IT-related Attitudes and Behaviors.

\section{Conclusion}

The digital transformation is accelerating and has implications for actors who perceive and understand the situation and its challenges in multiple ways while maintaining both cooperative and competitive relationships [17, 19]. Moreover, although promising for the digital transformation of SMEs, the growing universe of IT applications of all kinds requires significant efforts in a context generally not equipped to cope with business requirements, at once technological and managerial. As seen, a successful and consistent digital transformation requires investing not only in IT artifacts and infrastructure (e.g. hardware, software, networks, etc.) $[13,34]$, but also in strategic, intellectual, structural, formal and informal, social and cultural dimensions [6]. Thus, 
results underscored by the methodological approach taken highlight the importance to better understanding relational, social and cognitive aspects underlying the fruitful exchanges of knowledge between actors [41]. Hence, the GCM approach used in this exploratory study helped to better delineate efforts required by three groups of actors in a service ecosystem primarily dedicated to SMEs. As a result, actors are better able to put into place mechanisms to accurately assess the actual contribution of turnkey IT applications. Indeed, actual inputs and requirements may sometimes differ from the current discourse about SME needed to engage in a "Digital Agenda" and rush to address the urgency of the "digital transformation".

\section{References}

[1] Innovation Science and Economic Development Canada - Small Business Branch. Key Small Business Statistics - June 2016, 2016, access 03-09-2018; Available from:

https://www.ic.gc.ca/eic/site/061.nsf/vwapj/KS

BS-PSRPE June-Juin 2016 eng-

V2.pdf/\$file/KSBS-PSRPE June-

Juin_2016 eng-V2.pdf.

[2] Tsujimoto, M., Y. Kajikawa, J. Tomita, and Y. Matsumoto. "A Review of the Ecosystem Concept-Towards Coherent Ecosystem Design," Technological Forecasting and Social Change), in press.

[3] OECD. OECD Digital Economy Outlook 2017, 2017, access 03-09-2018; Available from: https://www.oecd-ilibrary.org/science-andtechnology/oecd-digital-economy-outlook2017 9789264276284-en.

[4] Cegarra-Navarro, J.G. and F. Dewhurst. "Linking Organizational Learning and Customer Capital through an Ambidexterity Context: An Empirical Investigation in SMEs," The International Journal of Human Resource Management, (18:10), 2007, pp. 1720-1735.

[5] Gregory, R.W., M. Keil, J. Muntermann, and M. Mähring. "Paradoxes and the Nature of Ambidexterity in IT Transformation Programs," Information Systems Research, (26:1), 2015, pp. 57-80.

[6] Chan, Y. and B. Reich. "IT Alignment: What Have We Learned?," Journal of Information Technology, (22), 2007, pp. 297-315.

[7] Neirotti, P., E. Raguseo, and E. Paolucci. "How SMEs Develop ICT-Based Capabilities in Response to their Environment: Past Evidence and Implications for the Uptake of the New ICT Paradigm," Journal of Enterprise Information Management, (31:1), 2018, pp. 10-37.
[8] Levy, M., C. Loebbecke, and P. Powell. "SMEs, Co-Opetition and Knowledge Sharing: The Role of Information Systems," European Journal of Information Systems, (12:1), 2003, pp. 3-17.

[9] Thorpe, R., R. Holt, A. Macpherson, and L. Pittaway. "Using Knowledge within Small and Medium-Sized Firms: A Systematic Review of the Evidence," International Journal of Management Reviews, (7:4), 2005, pp. 257-281.

[10] Dyer, J.H. and H. Singh. "The Relational View: Cooperative Strategy and Sources of Interorganizational Competitive Advantage," Academy of Management Review, (23:4), 1998, pp. 660-679.

[11] Reich, B.H. and I. Benbasat. "Factors that Influence the Social Dimension of Alignment between Business and Information Technology Objectives," MIS Quarterly, (24:1), 2000, pp. 81113.

[12] Preston, D. and E. Karahanna. "How to Develop a Shared Vision: The Key to IS Strategic Alignment," MIS Quarterly Executive, (8:1), 2009, pp. 1-8.

[13] Besson, P. and F. Rowe. "Strategizing Information Systems-Enabled Organizational Transformation: A Transdisciplinary Review and New Directions," The Journal of Strategic Information Systems, (21:2), 2012, pp. 103-124.

[14] Weick, K.E., Sensemaking in Organizations. 1995, Thousand Oaks, CA: Sage Publications.

[15] Trochim, W. and M. Kane. "Concept Mapping: An Introduction to Structured Conceptualization in Health Care," International Journal for Quality in Health Care, (17:3), 2005, pp. 187191.

[16] Rosas, S.R. and M. Kane. "Quality and Rigor of the Concept Mapping Methodology: A Pooled Study Analysis," Evaluation and Program Planning, (35:2), 2012, pp. 236-245.

[17] Barrett, M., E. Davidson, J. Prabhu, and S.L. Vargo. "Service Innovation in the Digital Age: Key Contributions and Future Directions," MIS Quarterly, (39:1), 2015, pp. 135-154.

[18] Tan, F.B. and R.B. Gallupe. "Aligning Business and Information Systems Thinking: A Cognitive Approach," IEEE Transactions on Engineering Management, (53:2), 2006, pp. 223-237.

[19] Vargo, S.L. and R.F. Lusch. "It's All B2B... and Beyond: Toward a Systems Perspective of the Market," Industrial Marketing Management, (40:2), 2011, pp. 181-187.

[20] Caldeira, M.M. and J.M. Ward. "Using Resource-Based Theory to Interpret the Successful Adoption and Use of Information Systems and Technology in Manufacturing Small and Medium-Sized Enterprises," 
European Journal of Information Systems, (12:2), 2003, pp. 127-141.

[21] Levy, M., P. Powell, and P. Yetton. "Contingent Dynamics of IS Strategic Alignment in Small and Medium-Sized Enterprises," Journal of Systems and Information Technology, (13:2), 2011, pp. 106-124.

[22] Kelly, S. and D. Scott. "Relationship Benefits: Conceptualization and Measurement in a Business-to-Business Environment," International Small Business Journal, (30:3), 2012, pp. 310-339.

[23] Zollo, M., E.L. Bettinazzi, K. Neumann, and P. Snoeren. "Toward a Comprehensive Model of Organizational Evolution: Dynamic Capabilities for Innovation and Adaptation of the Enterprise Model," Global Strategy Journal, (6:3), 2016, pp. 225-244.

[24] Brandenburger, A.M. and H.W. Stuart. "ValueBased Business Strategy," Journal of Economics \& Management Strategy, (5:1), 1996, pp. 5-24.

[25] Amiri, A.K., H. Cavusoglu, and I. Benbasat. "Enhancing Strategic IT Alignment through Common Language: Using the Terminology of the Resource-Based View or the CapabilityBased View?." in 36th International Conference on Information Systems (ICIS), 2015, Fort Worth, Texas, USA.

[26] Gottschalg, O. and M. Zollo. "Interest Alignment and Competitive Advantage," Academy of Management Review, (32:2), 2007, pp. 418-437.

[27] Kearns, G.S. and A.L. Lederer. "A ResourceBased View of Strategic IT Alignment: How Knowledge Sharing Creates Competitive Advantage," Decision Sciences, (34:1), 2003, pp. $1-29$.

[28] Ng, I.C. and S.L. Vargo. "Service-Dominant (S-D) Logic, Service Ecosystems and Institutions: Bridging Theory and Practice," Journal of Service Management, (29:4), 2018, pp. 518-520.

[29] Street, C., B. Gallupe, and J. Baker. "Strategic Alignment in SMEs: Strengthening Theoretical Foundations," Communications of the Association for Information Systems, (34), accepted.

[30] Celuch, K., G.B. Murphy, and S.K. Callaway. "More Bang for Your Buck: Small Firms and the Importance of Aligned Information Technology Capabilities and Strategic Flexibility," The Journal of High Technology Management Research, (17:2), 2007, pp. 187-197.

[31] Vargo, S.L. and R.F. Lusch. "Institutions and Axioms: An Extension and Update of ServiceDominant Logic," Journal of the Academy of Marketing Science, (44:1), 2016, pp. 5-23.
[32] Fujita, S., C. Vaughan, and S. Vargo. "Service Ecosystem Emergence from Primitive Actors in Service Dominant Logic: An Exploratory Simulation Study." in 51st Hawaii International Conference on System Sciences (HICSS), 2018, Big Island, Hawaii, USA.

[33] Dulipovici, A. and D. Robey. "Strategic Alignment and Misalignment of Knowledge Management Systems: A Social Representation Perspective," Journal of Management Information Systems, (29:4), 2013, pp. 103-126.

[34] Bradley, R.V., R.M. Pratt, T.A. Byrd, and L. Simmons. "The Role of Enterprise Architecture in the Quest for IT Value," MIS Quarterly Executive, (10:2), 2011, pp. 19-27.

[35] Sutherland, S. and S. Katz. "Concept Mapping Methodology: A Catalyst for Organizational Learning," Evaluation and Program Planning, (28:3), 2005, pp. 257-269.

[36] Kane, M. and S. Rosas, Conversations About Group Concept Mapping: Applications, Examples, and Enhancements. 2018, Thousand Oaks, CA, USA SAGE Publications.

[37] Kane, M. and W.M. Trochim, Concept Mapping for Planning and Evaluation. 2007, Thousand Oaks, CA, USA: SAGE Publications.

[38] Kruskal, J.B. and M. Wish, Multidimensional Scaling. 1978, Thousand Oaks, CA, USA: SAGE Publications.

[39] Everitt, B.S., S. Landau, M. Leese, and D. Stahl, Cluster Analysis. 5th ed. 2011, Chischester, UK: John Wiley \& Sons.

[40] Trochim, W.M.K. and D. Cabrera. "The Complexity of Concept Mapping for Policy Analysis," Emergence: Complexity \& Organization, (7:1), 2005, pp. 11-22.

[41] Grant, R.M. "Prospering in DynamicallyCompetitive Environments: Organizational Capability as Knowledge Integration," Organization Science, (7:4), 1996, pp. 375-387. 